\title{
ELEMENTS OF THE URBAN IMAGE IN LARGE HABITATS OF BUCHAREST
}

\author{
Alexandru GAVRIŞ \\ Academy of Economic Studies, Bucharest, Romania
}

\begin{abstract}
This article outlines the perception of the urban image at micro-territorial level based on an analysis of data resulting from a survey conducted in large human habitats in Bucharest. The identification so achieved reflects numerous spatial similarities of the perceptions of the urban image. The landmarks that the residents of Bucharest have in this respect are in line with the built areas as well as those related to the basic destinations of everyday life. This gives rise to quite a big issue: the people of Bucharest living in such large dwelling compounds are restricted to a superficial knowledge of space. They are impacted by a much too quickly changing urban policy and by permissive building investment rules that have lead to a variegated puzzle of post-communist restructurings where essence is attached to just trivial landmarks..
\end{abstract}

Key Words: Bucharest, large urban habitats, urban image, survey

\section{Perspective on urban image}

We live in a world where the image seems to be growingly important. The civilization of images as mentioned by Huyghe [1] is mirrored by cities more than ever before. Such images highlight the values they carry and they take the shape of lights, pictures, symbols or words which are as pleasant as possible and easy to associate. From street advertising to urban marketing strategies, images are necessary in order to draw the attention upon products that are more and more difficult to explore amongst the myriads of information. It is the images that point out the landmarks and identity of large urban communities by outlining their uniqueness and utmost importance for those targeted by such messages. This is done by defining the unique shape and character of the utmost importance for one who is sent the message to. But most important, the goals rely on promoting the respective city in the center of the global market and attract interest for helping its future development. But this isn't an easy task to accomplish and thus, local authorities need to rely first on the strengths accepted by the inhabitants which they manage. Therefore, clear strategic policies need to rely on studies which reveal the city landmarks in order to create a good city life.

Defining the image of a city lies in the interpretation of space and its components in their relationship with the local residents. The representativeness of landmarks is always subjective as it is affected by how the city residents approach their dwelling space. Likewise, it can be also complemented by urban policies that seek to add new values to a given area. In the course of their development, individuals discover a structural entity - an identity marked by shared values that gives them a sense of belonging more than anything else. Seen through its external forms, collective identity means an urban community that outlined its essential landmarks in a consistent manner. Otherwise said, identity develops as an element that gives coherence and continuity to such communities (Dematteis, 1994) and makes city look like structures and steady sets of actors and relationships that are forged in a given physical environment. (Fig.1). 


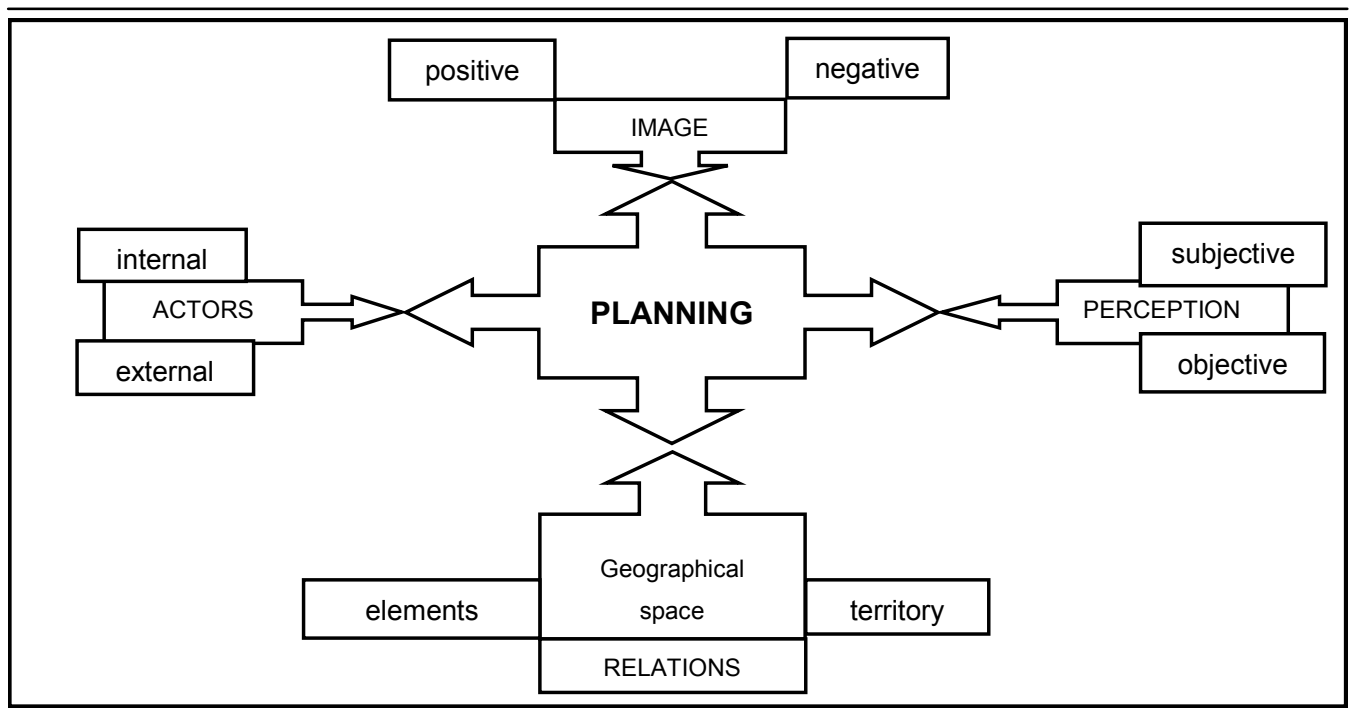

Fig. 1 - Position of urban image in urban planning (Gavriş, 2005, modified)

Differentiation emerges from values that accentuate the power and importance of certain hotbeds whose role is to organize the space by the attractiveness they exert but which are missing in this case. It is the individuals that picture out the landmarks in keeping with, not their importance, but their usefulness and significance for them. They so shape up mental images in order to better relate to the everyday necessities, to those items that determine their habitat, therefore a known area. The observers are those who determine a perception. The social class difference requires a choice of information that generates in its turn a number of spatially relevant activities and makes such activities distinct from each other (Kampschulte, 1999).

Associating images with an identity in economical terms causes a break in the cohesion between the two concepts. An urban image stemming solely from the economic dimension promotes only those interesting and significant elements that should be built on. It is differently understood, so that the identity of a place is the one where that particular place should be perceived. The identity of a place is a single set of identifiable associations of the place in question, which the administration wants to preserve or create (Rainisto, 2003).

Identity on the other hand would help preserve the existing elements and would take novelties on board with difficulty. Paradoxically enough, the better outlined the identity of a city is, the more attractive such a city turns out to be in terms of image and the more interesting in economic terms. An artificially built identity by the projection of images that are disconnected from the reality of the residents may cause problems as to the organization and management of such a city. For this reason, the strategies focusing on projecting the image of a city should be directly related to its residents and not separated from them as it usually happens.

One other issue arises from the fact that images are easy to distort and hard to embed in the minds of people. It takes time to create the image of a city or use its identity for development strategies. The countless failures in promoting cities can be explained by the ignorance of time and excessively sped-up processes. 
The theoretical landmarks of the urban image are to be found in the work of Kevin Lynch - The Image of the City: paths, districts, edges, nodes, and landmarks. The image of the city existed in the consciousness of any individual but the theoretical side and explanation of such an image were given by Kevin Lynch, alongside Christopher Alexander, Jane Jacobs. Underscoring a quantified and assessed existing image gave a new turn to urban research. Such an image does not contain just a prioritization of the architectural elements but also the thoughts they elicit in the minds of people, where residents of the city or not. They become an important feature of the urban product which they can modify. Such an element is achieved by what Kevin Lynch mentioned as the reading of the city. Depending on this reading, various landmarks take shape that reflect its meanings and outline its identity.

For example, the reading of the city of Bucharest is done function of the architectural elements we associate with the communist era and other historical elements against the background of the current transition. The resulting identity is difficult to express by the amalgamated elements and associations. And perhaps it is exactly this variegated diversity that defines this city located somewhere between the Orient and the Occident.

\section{Bucharest and its image}

How appealing a city is to others has always been a constantly topical issue. Ever since Bucharest started taking shape, it has been approached as a representative element. In this regard, the importance attached to the capital city and the desire to make it known to others has involved a strong need for shaping a positive image that would be consistent with the requirements of others.

If up until the $19^{\text {th }}$ century, Bucharest asserts itself by a multicultural image of its residents and by the status of a wretched but motley town - which is quite interesting to some of its visitors the interest in an international affirmation suddenly appears at the beginning of the $20^{\text {th }}$ century, particularly in the interwar period. Branded as a second Paris - "Little Paris"- Bucharest is the reflected image of the Parisian, French and Western values at the other end of Europe. In this regard, one may note the first elements of interest for the identification of mental landmarks and their branding at international level. It may well be said that the Bucharest of those times already was an important product on the European market of cities to visit, and the brand made by comparing it to Paris only underlined its attributes. There are not many references in the then and later literature to the negative elements of the city. Notwithstanding their presence in a bigger number and at a higher intensity than the values regarded as suitable for the name of Little Paris, the slums and workers' neighbourhoods were integrated in the positive image so created. From the viewpoint of a marketing approach, the interwar moment represents the best branding of the city.

This image was totally destroyed in the communist era as the values of the two ideological systems went counter to each other. However, even in that period, the image of the city and its representativeness were regarded as rather important landmarks. The zonal and regional competition Bucharest was involved in made the leaders of those times to shape up a high standard city in terms of architecture. Therefore, architecture during the communist era was the identity element round which its image was created and promoted. Thus, the main values of the then Bucharest derive from its architecture: buildings and streets. Furthermore, a zonal branding of the image was attempted during the last years of communism by the construction of the Civic Centre. An image of the image of the city is so created; an unmistakable landmark for both the nation and the entire world. However, this branding of the urban image values in Bucharest stress on architectural structures almost exclusively. For this reason, those values 
are currently perceived as negative ones by their association with the then ideology. But such a perception can be only found with most Bucharesters and not the rest of the population or common visitors. A telling example is the People's House, with a long-standing negative image for the Bucharest residents, but with a positive one for people coming from outside of the capital city.

As expected, the tumultuous changes in the history of the capital city have deeply affected the image and landmark identification elements. The balance between two ideological systems and multiple cultural areas left a negative mark on the city's identity. The opposition between old and new landmarks destroys the perception of elements, while also causing confusion and indifference to everything that might be regarded as a value.

Policy concerns for issues other than building on existing assets lead to no real importance being attached to the branding of the city's image in the transitional period. The landmarks of Bucharest were denied as they were associated with an ideology. The newly created landmarks have also come into contrast with each other and this dissolved the feeling of belonging to the urban values. The old historic centre of Bucharest suffers the most from such representativeness and value identity clashes.

By contrast, the situation is different in the large urban habitats (lanoş 2004, 2007, Gavriş 2005). Erected almost entirely in the communist period, such habitats pay a toll to that respective image - namely architectural blueprints. The landmarks of a neighbourhood are given by its marketplaces and commercial outlets. This identification with commercial centres is easy to understand. The absence or shortage of common products made most of the population (unconsciously) relate itself to commerce as one of the most important values. Even in recent years (2000-2007), and not surprisingly so, this type of landmark has become even more visible with the inauguration of hypermarkets and malls. We will not dwell on the residents of Bucharest neighbourhood identifying themselves with the commerce landmark as it would be an incomplete image. There are yet other values Bucharesters relate to but the emphasis seems to be laid on the commercial ones.

It would be difficult to say what the current image of Bucharest is. The multiple viewpoints that may be taken into consideration in various analyses as well as the research scale could outline various different projects. However, one may notice a tendency to refurbish the built areas with overrated elements that are as trivial as those from past periods. The image is therefore promoted with a much bigger stress on detail elements than the whole. The branded and accepted image should be expected to be given by further urban developments, with little or no planning involved.

\section{Image reflection in the large habitats}

The urban image as an expression of accumulated individual perceptions is reflected by the landmarks K. Lynch identified, which brand not just the physical space but also the social one. Iconic landmarks recognized by most of the population create a feeling of belonging that extends over social and cultural divisions. So, the reflection of the image in the large habitats derives from the social characteristics that impact and continue to shape it rather than anything else.

We conducted a survey on 700 people in five large urban habitats: Berceni, Tineretului, Balta Albă, Aviației şi Militari (Fig. 2), but in the end we kept only 541 with a good representation at Bucharest's level as well as areas level on which we have focused the analyses (Table 1). 
The features of landmarks existing in each area have been brought together in the analyzed questionnaires with a view to outlining an image that could be extrapolated to all habitats. One may note with the first landmark stated by respondents, the dominance of elements having a commercial significance, and the marketplace as a symbol stands out with $18 \%$. Surveys conducted on a large number of respondents in the Berceni area indicated a high rate of such a landmark as the hospital, which holds several such units.

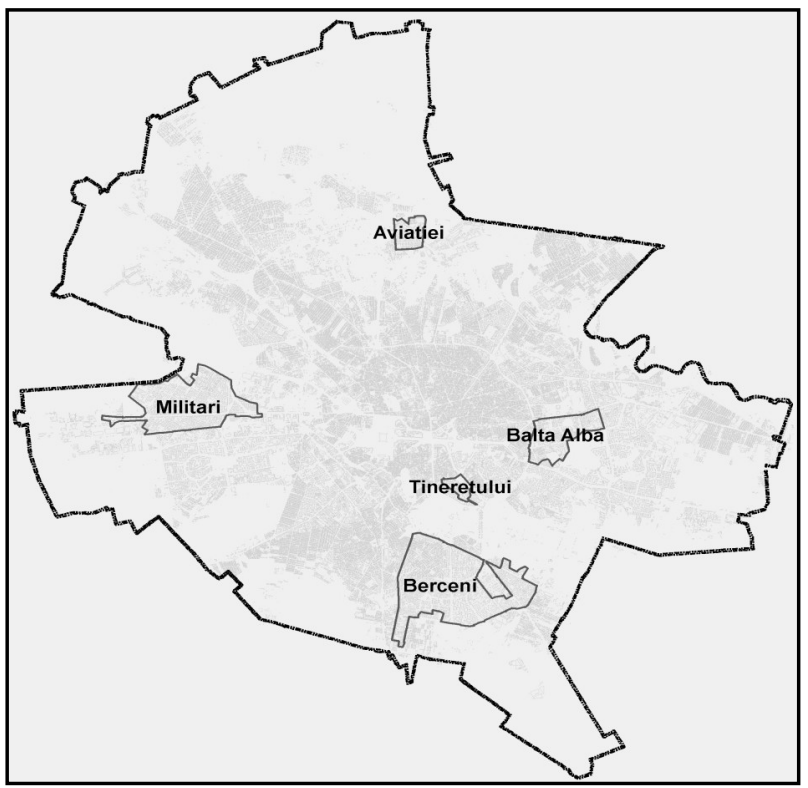

Fig. 2. - Large urban habitats analyzed

Structure of the survey

\begin{tabular}{|c|c|c|c|c|c|c|c|}
\hline \multicolumn{2}{|c|}{ Sex - \% } & \multicolumn{4}{|c|}{ Age (years) - \% } & \multicolumn{2}{|c|}{ Property - \% } \\
\hline Female & Male & -25 & $26-40$ & $41-60$ & over 60 & Tenant & Proprietor \\
\hline 59 & $\overline{41}$ & 21 & 24 & 33 & 22 & $\overline{11}$ & 89 \\
\hline \multicolumn{3}{|c|}{ Past residence - $\%$} & \multicolumn{5}{|c|}{ Education - \% } \\
\hline Bucharest & $\begin{array}{c}\text { Other } \\
\text { city }\end{array}$ & Rural area & & Lower & $\mathrm{Mec}$ & & Higher \\
\hline 75 & 15 & 10 & & 10 & & & 32 \\
\hline
\end{tabular}

Source: surveys conducted by author 2005-2008

High rates of nearly $6 \%$ were also seen with malls and convenience stores that are however overtaken by hypermarkets whose numbers are growing in high-density areas. Commercial landmarks (mall, convenience store, hypermarket, marketplace) put together account for nearly $40 \%$ of the responses and this shows the place taken by commerce in the life of the largehabitat population. No surprise in how the development of the city goes along these lines, however the novelty and lack of specialization of such objects indicates the absence of other long-lasting icons. Habitats are therefore defined as commercial towns in themselves as 
residents seem to be focused on commerce.

Of all path-type landmarks, the street prevails especially in habitats (Berceni, Militari) with wide avenues clearly cutting their way through the myriads of high rises flanking them. One may also include in the image created by the traffic landmarks such transport points as the airport, the bus station, the filling station, bus routes and junctions, these latter ones being defined as secondary elements. The traffic landmarks so explain people's increased motility in performing their various activities and they guide the sense of perception of the habitat limits.

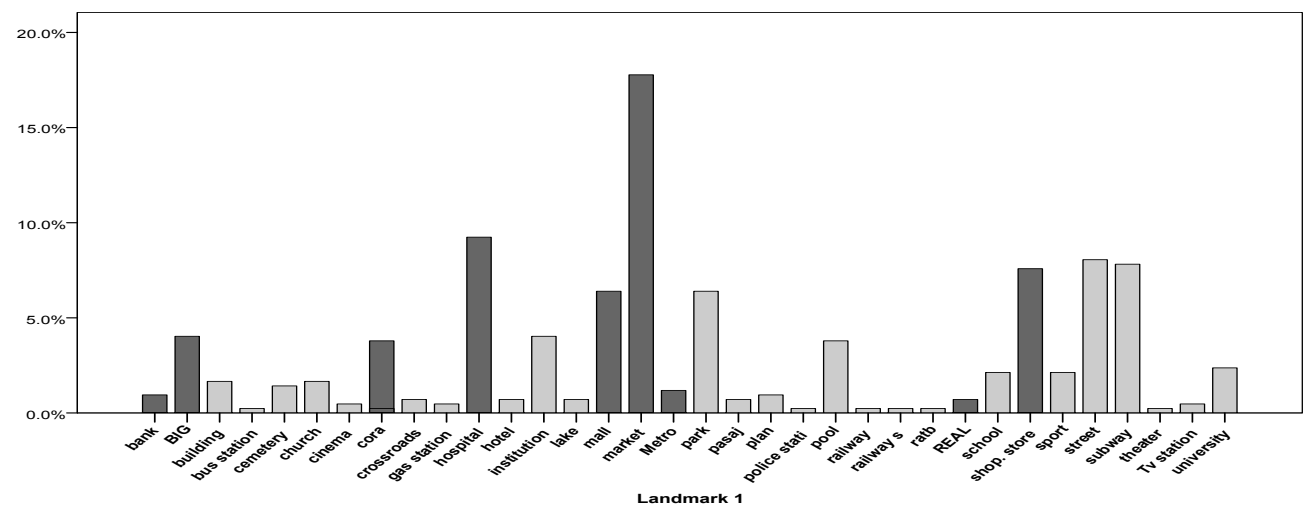

Fig. 3 - Landmarks of the habitats (1)

The subway next to the landmark passageway are the only junction-type variables that appear as an expression of the inflow/outflow concentrations. Overlaying traffic axes, they may accentuate the importance of streets even more. The subway connectivity relates to the commercial centres. This landmark is the interface between commerce and streets, therefore between commercial icons and the ways to them. These two items put together account for $60 \%$ of the perception of the habitat, which is one more indication of the social space being closely connected to commercial activities.

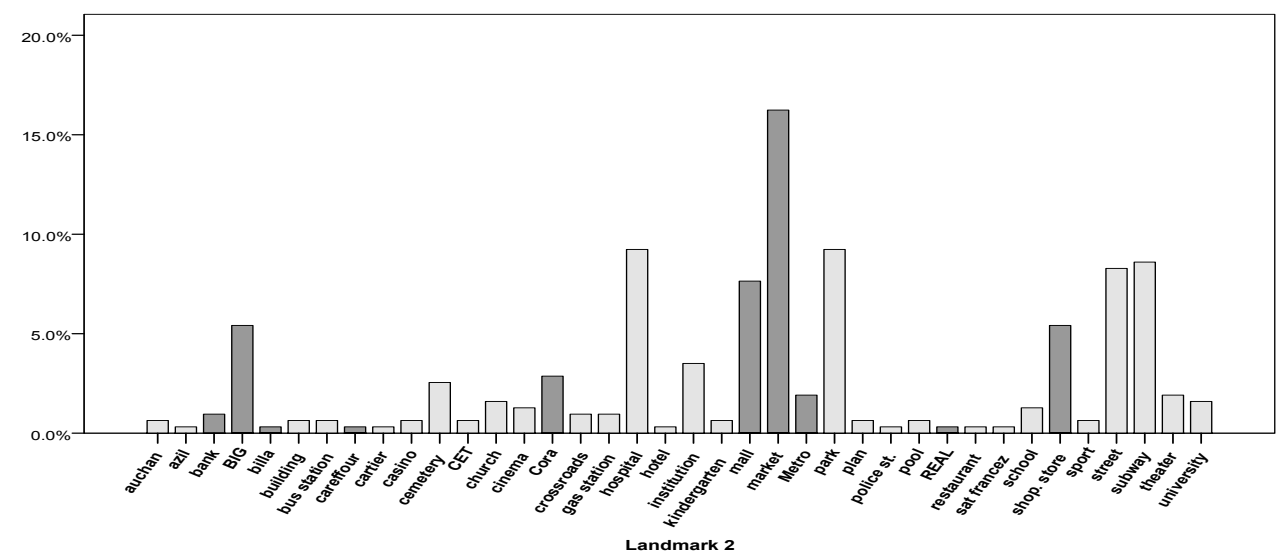

Fig. 4 - Landmarks of the habitats (2) 
In terms of fixed but differently expressed landmarks, one may mention various institutions, universities, buildings, plants, schools, which appear as obvious elements in the delineation of a place by their functionality and relevance for the questionnaire. Dwellers of a habitat guide themselves based on such objects, and they so identify temporary landmarks. Such a delineation has a variable nature as it is preserved overtime so long as the landmark is in a direct relation with the resident through the function it fulfils. It may be preserved for further periods of time but its importance decreases. One element that can strike the difference between these statements is the size of the object in question. The bigger the size, the easier to notice, but that requires a good knowledge of that particular area. Some of the survey respondents were unable to tell the names of universities or plants in their own areas. As they emerge too fast, they fail to be correlated functionally and they are just expressed in local jargons.

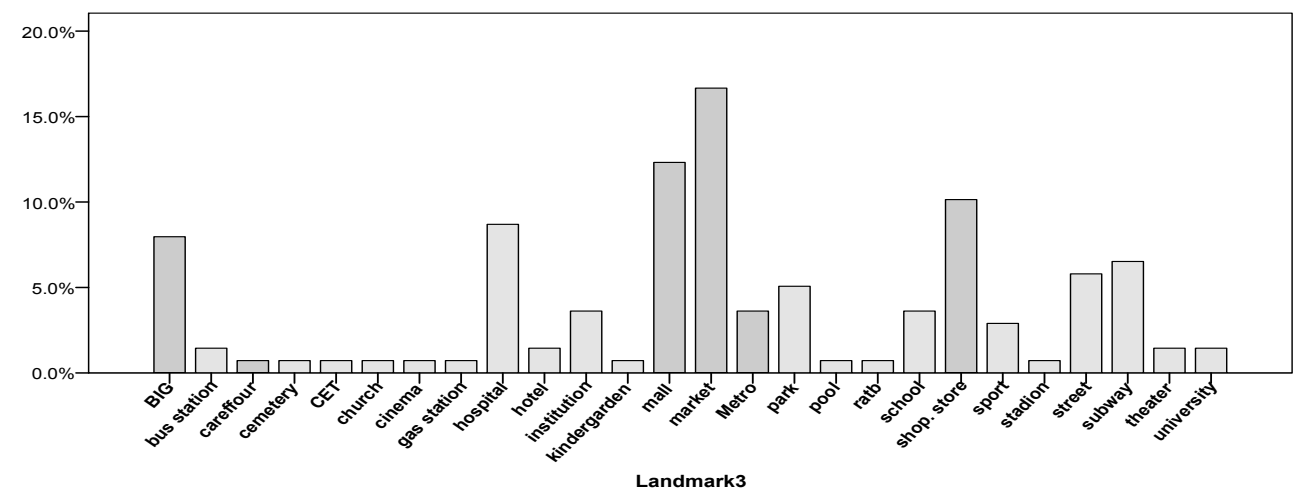

Fig. 5 - Landmarks of the habitats (3)

Landmarks perceived as limits such as: lakes, railtrack or parks are low in the standings of people's perception of the Bucharest habitat. They are unable to define the space such landmarks belong to and they most of the time evidently undersize the limits of their neighbourhoods. The knowledge of an area so restricts to just the big elements - park $-6 \%$ and probably lake, but they take the backseat. This indicates a limited recreation areaorientation. An exception to the above is the public pool, a top landmark in the Berceni habitat, even if it is an object and not a limit.

As regards the expression of the second and third landmark, no significant changes can be reported in the perception of the image of Bucharest habitats. Only such landmarks appear that define the area where the interview was taken. Overall, the two new tables complement the image of commercial objects being rated as the most important ones.

Distinctions between images of analyzed habitats are due to perceptions related to age, dwelling time, professional background, previous residence, and the holistic image generated by their actions impacts the behaviours of the inhabitants and echoes to the outside world. All this would follow all the city's components (Fig 6.).

The resulting image for each habitat is a little differentiated but it highlights the development lines of the area. 


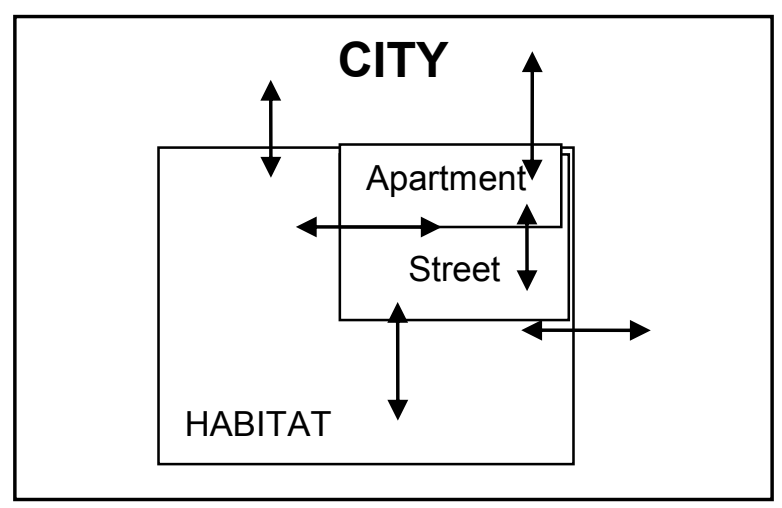

Fig. 6 - Levels of urban representation

(T. Schumacher 1978, modified)

In the large Berceni habitat, commercial outlets are dominant under conditions when the served population is numerous and they are spread all throughout that area. The marketplaces are located along an approximately median line of the habitat, and the large-sized commercial centres show a longitudinal expansion focusing on extremity areas. As shown earlier in the habitat structure, the high number of hospitals is an element difficult to ignore and such landmarks were mentioned as secondary to the commercial ones. Despite the non-priority nature of this secondary landmark within everyday activities, it stands out by the extension and size of the buildings and it is so difficult to overlook. The other, less important, landmarks are the result of the complexity of the interview. For this reason, the public pool is rated at over $8 \%$ as a secondary landmark and under $2 \%$ within landmarks 1 and 3 . Given its seasonal function, it inevitably places lower, but it however has a strong significance no matter the ages of the respondents.

The large Militari habitat is characterized by the dominance of the street and junction landmarks. This also results from the functional structure of that area being quite tied with the segmentation entailed by the luliu Maniu Boulevard, where the subway stations and junctions play the role of channelling and dispersing the inflows into the said boulevard. The impact of buildings and institutions is bigger in Militari than Berceni and people are more likely to know their names. But this restricts to only schools, police stations and university - a quite clear indication of identity icons missing in that area. Furthermore, even if the centre of the habitat is clearly outlined, the extremes vary and have no major bearing on the local residents.

The small but highly populated areas of the other habitats located in the proximity of parks led to an orientation towards this specific landmark, as shown in all the three $6 \%$-rating responses. The 3 habitats, Tineretului, Aviației and Balta Albă carry a more dissipated perspective of the image values, which is less centred on mundane commercial objects. For example, banks in the Aviatiei area appear as very important landmarks although there are more than 7 of them stretching over a small area and they are always located in heavy-traffic areas. They are complemented here and in the other 2 habitats not by large stores but convenience stores people feel emotionally closer to. This is in keeping with the higher ratings given by people who favour such stores. The overall picture suggests individualization centred on recreational areas. 
The qualitative perception centred on recreational spaces reinforces the positive image of the area in question. The image is dominantly positive in Aviației and Balta Albă - over $80 \%$ of the respondents have a high appreciation of their neighbourhoods. The variables are a bit different because Aviației shows a uniform appearance and quality of the buildings and balanced proportions of the residents' occupations which focus on services or higher activities, while Balta Albă displays a higher level of community interaction (less manifest in the questionnaires). Their positive image is strengthened by the good assessment of the cleanliness of the streets. The responses for this variable are $50 \%-50 \%$ for good and so-so.

Tineretului is looked upon as a quality area than enjoys a good perception, with $60 \%$ of the respondents saying it is good and $32 \%$ acceptable. The positive nuance stays when it comes to the streets they live on, but the assessment of the street quality goes down: only $47 \%$ think they live on good streets, whereas $37 \%$ say their street is acceptable. If in the other two habitats, the negative responses about the dwelling conditions are insignificant $-1 \%$, Tineretului however scores a higher rate: $15 \%$ for the street assessment, but with a positive image kept - and only $1 \%$ think it is a bad area.

The negative image is not a determining factor for the analyzed areas. Even in the large habitats with possible issues, the perceived landmarks do not affect the area in a negative manner. Militari has a positive image but people there are indifferent to a certain extent and they accept the given situation. The responses are more or less evenly distributed: $42 \%$ think that the image of the neighbourhood-area is a positive one, $50 \%$ opine they live in an acceptable area, and nearly $7 \%$ point out negative elements in Militari. The negative rates grow as the distance to the downtown area grows while the distance to the western and southern limits diminishes. The singles' homes in the Cascadelor area are attached to a strong negative image, and the degradation continues at micro-spatial level. As a whole though, there is a more or less even distribution by categories of responses as o the street assessment $-30 \%$ of the respondents are happy with the street they live in, with a higher proportion of them in the northern and eastern parts of the area.

Varied assessments are reported in the large Berceni habitat, which depend on the knowledge of that area and the limits up to which the respondents imagined the space in question. There is a positive assessment overall $-49 \%$, but also a significant proportion of responses (41) expressing a relative acceptance. As concerns the negative connotations, $10 \%$ think that Berceni is repulsive and for those in Militari, the topophobic elements are correlated with certain parts of the habitat being too expanded over the entire area. One supporting argument is that most respondents from the Resita marketplace area and the extension into the street, regarded as central for the image of Berceni, have a negative image and they do not take into consideration the areas near them which are well maintained and well seen by locals. Such responses are better differentiated in terms of street assessments where $40 \%$ have a good opinion of the conditions, $42 \%$ a fair one, and $18 \%$ are totally unhappy with how their street is taken care of and the display of the high rises stretching along it.

Strongly reflected in the media and scientific research works by their negative attributes, the large urban habitats have positive and satisfactory characteristics in the eyes of the residents. However, the positive side of the image and dwelling fund gets degraded as against other areas and, more recently, new residential compounds built with private money. The comparison between the habitat and state-built residential compounds that emerged after 1990 - Brancusi - places the habitat ahead of the rest. However, there are other residential habitats (Ferentari) that are perceived negatively as a whole by people living in that area. 
It is important to say that the perception of an area of people who live in that particular area is much better than the perception of passers-by or those who do not live in its proximity. As such habitats were built form people coming from rural areas who had trouble to find a dwelling, they are accepted by their features, and the discontent grows function of age, education and income.

The image of a habitat depends on its morphological and functional elements. The buildings and the street network outline analogical expressions of the landforms, while bringing in negative features though: canyon-like streets, monolithic blocks, intersections - jams. Changing the image of a habitat would require intervening upon the above mentioned elements. Efforts are being made in this respect but, strangely enough, the effects are quite to the opposite of those pursued. Furthermore, such interventions are not always in line with the opinions and thoughts of the locals and there is no interaction between the players involve in the construction of the city and of the habitats.

One may therefore conclude that the overall image is a positive one but that there is a visible descending tendency as a result of the lack of interventions to build on and make the correlation with the overall spirit of the area.

\section{References}

DEMATTEIS G. (1994), Urban identity, city image and urban marketing, in G.O. Braun, Managing and Marketing of Urban Development and Urban Life, Ed. Dietrich Reimeri Verlag, Berlin, p. $998-1016$.

GAVRIŞ A. (2005), Dysfunctions in the large urban habitat Berceni - Bucharest, Revista Jurnalul Economic 16, p. 119-138.

HUYGHE R. (1971), Puterea imaginii, Ed. Meridiane, Bucureşti.

IANOŞ I. (2004), Dinamica urbană : aplicații la oraşul şi sistemul urban românesc, Ed. Tehnică, Bucureşti.

IANOŞ I. (2007), A Major Challenge for Romanian Towns: The large habitats, in: Pomoroy, G., Webster G. (eds), Global Perspectives on Urbanization, University Press of America, Inc., Pennsylvania, p. 106-135.

KAMPSCHULTE A. (1999), Image as an instrument of urban management, in Geographica Helvetica, H. 4, p. 229-241.

LYNCH K. (1960), The Image of the City, Cambridge MA, The MIT Press.

POWER A. (1997), Estates on the edge. The social consequences of mass housing in Northern Europe, MacMillan Press Ltd., London.

RAINISTO S. K. (2003), Success Factors of Place Marketing: A Study of Place Marketing Practices in Northern Europe and the United States, Doctoral Dissertation, Helsinki University of Technology, Institute of Strategy and International Business, Helsinki.

SCHUMACHER T. (1978), Construzioni e strade: note sulla configurazione e sull'usso, in Machedon F. (2006) Metode de analiză morfologică a țesuturilor urbane, Ed. Universitară "Ion Mincu", Bucureşti, p.147-165.

Received at : 20.03 .2010

Revised at: 10.05 .2010

Accepted for publication at: 10.06 .2010 